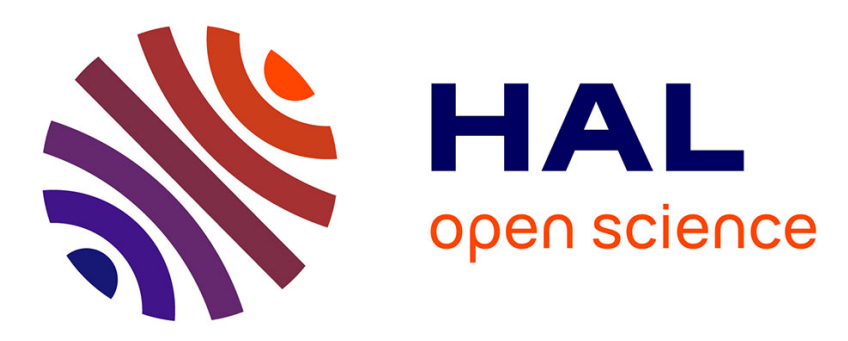

\title{
Hypnosis for labour and childbirth: A meta-integration of qualitative and quantitative studies
}

Juliette Gueguen, Caroline Huas, Massimiliano Orri, Bruno Falissard

\section{To cite this version:}

Juliette Gueguen, Caroline Huas, Massimiliano Orri, Bruno Falissard. Hypnosis for labour and childbirth: A meta-integration of qualitative and quantitative studies. Complementary Therapies in Clinical Practice, 2021, 43, pp.101380. 10.1016/j.ctcp.2021.101380 . hal-03230884

\section{HAL Id: hal-03230884 \\ https://hal.science/hal-03230884}

Submitted on 14 Dec 2021

HAL is a multi-disciplinary open access archive for the deposit and dissemination of scientific research documents, whether they are published or not. The documents may come from teaching and research institutions in France or abroad, or from public or private research centers.
L'archive ouverte pluridisciplinaire HAL, est destinée au dépôt et à la diffusion de documents scientifiques de niveau recherche, publiés ou non, émanant des établissements d'enseignement et de recherche français ou étrangers, des laboratoires publics ou privés. 


\section{quantitative evidence to inform patient-centred care}

Authors and affiliation

Juliette Gueguen ${ }^{1}$, Caroline Huas ${ }^{1,2^{*}}$, Massimiliano Orri ${ }^{1}$, Bruno Falissard $^{1}$

${ }^{1}$ Université Paris-Saclay, Univ. Paris-Sud, UVSQ, CESP, INSERM, France

${ }^{2}$ Fondation santé des étudiants de France, Paris, France

* Corresponding Author

Caroline Huas

Fondation Santé des étudiants de France

8, rue Emile Deutsch de la Meurthe

75014 Paris

$0033+603435905$

E-mail: caroline.huas@fsef.net

Conflict of interest statement: none of the authors have any conflict of interest to report regarding the topic of the article

Funding information $=$ none

Abbreviations: CAM complementary and alternative medicines

Ackowledgment= Angela Verdier for the traduction and Dr Perrine Capmas for her wise advices.

Author contribution statement: .JG and BF designed the analyses JG and $\mathrm{CH}$ selected the articles and extracted the data. JG, $\mathrm{CH}$ and MO wrote the manuscript. All authors reviewed the manuscript. 


\section{Hypnosis for labour and childbirth: a meta-integration of qualitative and quantitative studies.}

\section{Highlights}

- $\quad$ This is the first study to combine quantitative and qualitative results on hypnosis during labour and childbirth using an integrative model. Combining qualitative and quantitative findings showed the legitimacy of both paradigms with equal levels of evidence.

- $\quad$ Although both qualitative and quantitative studies have evaluated hypnosis in labour and childbirth, the outcomes addressed by these two types of study only slightly overlap.

- $\quad$ Results suggest that hypnosis could alter women's expectations and self-evaluation (response shift).

- $\quad$ Patient-centred instruments to explore response shift are required.

- Hypnosis can be presented as a technique enabling patients to have a positive birth experience. 


\section{Abstract}

Background and purpose: Hypnosis in labour and childbirth is a complex intervention. Both qualitative and quantitative assessment methods have been used, but have targeted different outcomes. We followed a synergistic approach and a reconciliation strategy to further understand and evaluate this intervention.

Methods: A mixed-method analysis of quantitative and qualitative evidence was conducted. The assessment of efficacy was based on a recent Cochrane review (9 trials, 2954 women randomised). Four qualitative studies and 4 case studies were included.

Results: The outcomes addressed by the qualitative studies (mostly concerning maternal experiences) and in the quantitative studies (mostly concerning analgesic use) overlapped slightly. Discrepancies across results from the two study types suggested that response shift issues could occur.

Conclusion: Patient-centred instruments exploring response shift issues would be of great value. Hypnosis can be presented as a technique enabling patients to have a positive birth experience.

Keywords: birth; delivery; hypnosis; mixed method; patient-centred; evidence-based practice.

Conflict of interest statement: None of the authors have any conflict of interest to report on the topic of the article.

Funding information: none.

Abbreviations: CAM, complementary and alternative medicine. 


\section{Introduction}

An increasing number of women are showing interest in complementary and alternative medicine (CAM) during pregnancy (1). This is probably due to the desire "to prepare themselves physically, emotionally and spiritually for labour and birth" (2), to earlier adverse experiences, as well as to the disadvantages of epidural anaesthesia (e.g. discomfort during the placement of neuraxial analgesia, or numbness of the legs) $(3,4)$. To holistically evaluate the efficacy of hypnosis, both clinicians and researchers need to take the complexity of reasons for which women turn toward CAM into account.

Hypnosis is defined as a state of inner absorption, concentration and focused attention (according to the American Society of Clinical Hypnosis) (5), during which a person is highly responsive to suggestion. It follows different steps (induction, deepening, closure) and uses different techniques (e.g. focused attention, metaphors, suggestion) (5).

The main theoretical model underlying the use of hypnosis for pain management during labour and childbirth is the Dick-Read fear-tension-pain syndrome model (6) (Figure1). The model states that hypnosis can help women change their former beliefs concerning childbirth, resulting in an increased feeling of confidence, lesser anxiety, reduction in muscle tension, and ultimately also in pain. However, the different stages and aspects of the intervention (e.g. relaxation phase, suggestion, patient-therapist interaction) remain unclear. This model supposes that hypnosis has a direct effect on the sensory component of pain, achieved via techniques raising the pain threshold by a recalibration process before the occurrence of pain, 
thus leading to less perceived pain. This recalibration could in turn lead to a reduced use of pharmacological analgesics.

So far, evidence on the efficacy of hypnosis in labour and childbirth has been based on a recent Cochrane review of nine trials ( $n=2954$ women randomised) testing the efficacy of hypnosis for pain management during labour and childbirth (7). Briefly, the Cochrane review showed that:

- All studies compared self-hypnosis $(n=8)(8-15)$ or hypnotherapy $(n=1)(16)$ with a control group, which, depending on the study, was standard care $(n=3)(8,9,16)$, standard childbirth preparation $(n=3)(10-12)$, and attention control $(n=3)$, (relaxation (13), supportive counselling (14) and supportive psychotherapy (15)). Sample sizes ranged from $38(11)$ to $1222(9)$

- Women in the hypnosis groups were less likely to use pharmacological pain relief or analgesia than those in the control groups (average risk ratio (RR) $0.73,95 \% \mathrm{Cl}=0.57-0.94$, eight studies, $n=2916$ ). But no significant effect of hypnosis on the use of epidural/neuraxial block was reported ( $\left.R R=0.81 ; I_{95}[0.51,1.29]\right)$, whatever the type of comparator. Sensitivity analyses excluding the quasi-randomised trials provided similar results $\left(R R=0.79 ; I_{95}[0.50,1.27]\right)(13,16)$.

- No clear differences in satisfaction with pain relief or feelings of coping were evidenced.

- No serious adverse events were reported in any of the studies.

However, hypnosis in labour and childbirth is a complex intervention, and its evaluation raises methodological issues (17). Firstly, the mechanisms of action of hypnosis on pain remain unclear. Hypnosis could impact both the ability to cope with pain and the different components of pain (affective, sensory) by way of different techniques (focused attention, 
metaphors, suggestion). Secondly, interventions are heterogeneous, which is a concern when studies are pooled in meta-analyses. For example, hypnosis can either be delivered in person by a practitioner, or self-induced by the trained expectant mother herself. Furthermore, selfhypnosis training courses are themselves heterogeneous (organized in individual or group sessions, with variable numbers of sessions, with or without a partner, sometimes involving an audio recording for home practice). Thirdly, appraising the numerous relevant outcomes remains an issue. In the trials, the main outcomes (as defined by the investigators) primarily concern pain management rather than the birthing experience. However, these outcomes may be less relevant for the patient. The concept of patient-centredness has grown from a theoretical approach into a core dimension of what is considered as high-quality health-care $(18,19)$. Taking the patient's perspective into account is a main component of patient-centred care. Several definitions have been used, often quite heterogeneous (20). For instance, Gerteis et al. have identified 6 dimensions of patient-centred care (definition used by the US Institute of Medicine (IOM)), in particular "Respectfulness to patients' values, preferences, and expressed needs" and "Ensuring physical comfort stresses the importance of correct management of pain and other discomforts for patients to achieve physical comfort" $(21)$. Patients seem to be satisfied with this kind of approach (22).

These issues highlight the fact that no single method is sufficient to assess such a complex intervention. As suggested by certain authors, evaluations should include a variety of methods "counterbalancing their individual strengths and weaknesses to arrive at pragmatic but equally rigorous evidence" (23). In particular, the use of qualitative methods exploring the patient's perspective seems necessary to integrate and complement the quantitative findings derived from randomised controlled trials (RCTs) $(24,25)$. 
Based on a mixed method approach (26), the objectives of this study were: (1) to perform a thematic analysis to synthesize the qualitative evidence on the experience of hypnosis for labour and childbirth; (2) to integrate quantitative data (from the Cochrane review (7)) and qualitative data into a holistic model.

\section{Methods}

We performed a systematic mixed-method review. The literature search, the quality appraisal, and the method of analysis were specific to qualitative data. On the basis of the Cochrane review, we considered the 9 quantitative studies included in Madden's study (7). Results were then compared across methods and integrated into a comprehensive model.

\subsection{Qualitative studies}

An electronic database search was performed (PubMed, CINAHL Plus, PsycINFO - endpoint 12/2017), and supplemented by a manual search. JG and $\mathrm{CH}$ independently screened titles and abstracts, then full texts, of all potentially relevant reports on qualitative studies exploring women's experiences of hypnosis for labour and childbirth. Studies addressing only the induction of labour or the effect of the intervention in the post-partum period were excluded (kappa=0.76). Disagreements were resolved by discussion. The quality of the studies included was assessed on the CASP (Critical Appraisal Skill Program) tools, except for case reports, since they do not follow qualitative methods (and should therefore be interpreted with caution). JG and $\mathrm{CH}$ summarised the studies included using thematic analysis, organising study findings 
according to descriptive codes and then grouping them into a hierarchical structure based on similarities and differences. Then, these similarities and differences between the codes were sought for in order to group them into a hierarchical structure. We kept very close to the original findings of the studies included and did not develop "third-order interpretations" at this stage. Then, the content of the case reports was used to triangulate the qualitative findings. As the question of the benefit/risk balance is fundamental for the resort to complementary medicine, safety was studied separately.

\subsection{Integration of qualitative and quantitative evidence}

A careful comparison, i.e. "conscious and intentional consideration of the findings, commonalities and differences between the two datasets", was performed using an iterative process in which qualitative and quantitative findings were not merged but meshed $(27,28)$. We organized these results according to whether the qualitative and quantitative findings were concordant, discordant or complementary, following the convergent meta-integration framework proposed by Frantzen and Fetters (28). An integrative model of the mode of action of hypnosis was developed, incorporating previous knowledge and our original findings. For each component in the model we determined whether it was supported by qualitative data, quantitative data or both.

\section{Results}

\subsection{Qualitative evidence}


Four qualitative studies (2,29-31) and 4 case studies (32-35) were included (Figure 2).

The qualitative studies reported the experience of $1(30)$ to 16 women (31) and the case studies from $1(33)$ to 5 women $(10-12,14,15,34,35)$. Women were taught self-hypnosis in all the studies, predominantly in individual sessions, but also in group sessions (31). In one study and 2 case studies, the additional presence of the therapist during labour and childbirth was reported $(29,30,33)$ (see Table 1 for details). In one case study, the mother was taught how to use hypnosis for another indication, and was able to use it for labour (35). Only the most recent qualitative studies met most of the quality criteria $(2,31)$ (Table 2$)$.

We organized the results into three chronological categories ("before labour", "during labour" and "after labour"), with the first two categories divided into 3 subthemes ("mode of action", "results" and "levers and difficulties").

Before labour, changes in pre-existing beliefs and a decrease in anxiety appeared to enable women to gain confidence and control so that they were less likely to ask for a Caesarean section. Two main levers were identified: social and medical team support and repeated and personalized training. During labour, increased confidence, together with the ability to relax, being more alert and focused, visualizing a safe place to go and changing the pain into a sensation of pressure appeared to shorten the time of labour, reduce tiredness and turn labour and birth into a positive experience. This was sustained by improved communication with the medical team. Difficulties were also reported, such as the misinterpretation of the stage of labour by the admission staff as a result of the relaxed state of the women in labour, and disappointment as a result of raised expectations that were not fulfilled. This underlines the importance of supporting women who choose to use hypnosis during childbirth. After 
labour, hypnosis was reused in other contexts and stressful situations, such as breastfeeding difficulties (Table 3).

The case reports underlined the ability of women to remain calm during labour and to make it "look easy" (33-35). One case report mentioned the effect of hypnosis on blood pressure, and also reported that the woman did not realize when the baby was born and needed to be aroused from her "trance" (33). Third-party perspectives were sometimes reported: one woman mentioned her husband's impressions and how amazed he was, and another mentioned that both the family (husband and parents) and staff were surprised by the calm and competent manner in which the mother was coping $(34,35)$.

\subsection{Safety}

Concerning safety, no serious adverse event was reported in any of the studies - quantitative or qualitative (7). This is reassuring concerning the safety of the practice, at least during labour and childbirth. Nevertheless, post-partum complications of hypnosis associated with the use of in-labour suggestion have been previously reported (36). In this case report, the woman was encouraged to count the number of breaths during uterine contractions; but it appeared that it persisted into the postnatal period, leading to increased anxiety. A series of factors could have contributed to the continuing "counting strategy" after labour. For example, excessive tiredness following a prolonged period without sleep, lengthy labour, and an imperfect epidural analgesia could all have contributed to the woman remaining in a state of trance. Hypnotic trances need to be ended in an appropriate manner to allow the patient to move on. 


\subsection{Integrating qualitative and quantitative evidence}

Most of the themes emerging from the qualitative studies were not assessed in the quantitative studies. In the quantitative studies, primary outcomes mostly concerned pain intensity/use of analgesia and birth complications, whereas in the qualitative studies, the main themes were maternal skills and experiences (Figure 3).

Nevertheless, 3 themes related to maternal skills and experiences were addressed in some quantitative studies (8-12): (1) Fear, anxiety, and a feeling of confidence and ability to cope, as reported before labour; (2) a feeling of confidence and ability to cope, as reported during labour; (3) Satisfaction and experiences reported after childbirth.

Similarities and discrepancies between qualitative and quantitative findings and fit assessments for these 3 themes are shown in Figure 4. The following aspects emerged:

$1 /$ The feeling of confidence and ability to cope were reported to be enhanced by the hypnosis intervention before labour in 6 qualitative/case studies (2,30-34). Only one RCT addressed this outcome, with similar results: greater perceived ability to cope during childbirth after course completion in the hypnosis group (11). Another RCT reported lower actual, as opposed to anticipated, levels of fear and anxiety during labour and childbirth in the intervention group (8).

2/ The feeling of confidence and ability to cope experienced during labour and childbirth was reported to be greater in all qualitative and case studies $(2,29-34)$. Three RCTs addressed this 
outcome, one found opposite results, with poorer intra-partum coping skills reported in the hypnosis group $(p=0.02)(11)$, and 2 reported no difference $(8,10)$.

3/ Satisfaction and the experience of childbirth were reported to be enhanced in most qualitative studies $(2,29,30,32-34)$. One study reported feelings of frustration and disappointment among women whose experiences did not meet the expectations that had been raised by the self-hypnosis training (31). Quantitative studies found mixed results. One $\mathrm{RCT}$ reported that the women in the hypnosis group had a better experience of childbirth (mean Wijmas-Delivery Experience Questionnaire score of 42.9 vs 47.2 in the relaxation group and 47.5 in the care-as-usual group; $p=0.01)(37)$. One RCT reported a trend towards more satisfactory labour with women who used hypnosis ( $52 \%$ versus $23 \%, p=0.08)(12)$. Two RCTs reported no difference between groups for perceived experiences (10) and satisfaction with labour pain relief (8).

Insert here: Figure 4: Similitudes and discrepancies between results of qualitative and quantitative studies.

It can be noted that in the Downe study, where partners were invited to the home training sessions in hypnosis, no significant results were reported for the main outcome (8); however partners were reported to have participated in only $\sim 25 \%$ of the home sessions.

Figure 5 illustrates how qualitative and quantitative findings were coherent with the components of the theoretical model describing the mode of action of hypnosis in different ways.

Insert here Figure 5.Theoretical model for how hypnosis might work. 


\section{Discussion}

\subsection{Main results}

- Qualitative studies: The main idea was that hypnosis could enable women to turn labour and childbirth into a positive experience. Lack of support appeared to discourage women from using self-hypnosis during the actual labour process. Support and recognition from the partner and/or the medical team appears to be an important factor to sustain women in their choice to use and draw benefit from hypnosis.

- Quantitative studies: A meta-analysis showed no significant differences between women in the hypnosis group and those in the control group for the use of epidural/neuroaxial block, nor for the other outcomes explored (7). Great heterogeneity was observed across studies for the interventions, the populations, the settings and the choice of the main outcome.

- Integrating qualitative and quantitative evidence: the main strength of this study was that it integrated results derived from qualitative and quantitative methods. It thus offered different perspectives on the same issue; it was also limited because of the few overlaps between the outcomes investigated by the qualitative and quantitative studies. Recognition of this insufficient overlap could contribute to encouraging communication between qualitative and quantitative researchers, and to pinpointing the importance of patient-centred research. 
- No serious adverse events were reported in any of the studies (quantitative or qualitative), pointing to the safety of hypnosis during labour and childbirth.

\subsection{Different outcomes}

The themes emerging from qualitative studies were mostly different from the outcomes assessed in the RCTs. This stresses the fundamental difference between qualitative and quantitative approaches. Assessment of the emotional component of pain and subjective experience is overlooked in most RCTs, although different components (sensory and emotional) and the existence of several facets of pain are acknowledged, and dedicated instruments are available (38). In such situations, performing a qualitative study prior to the quantitative study would enable RCT outcomes to be refined, combining both clinician and patient perspectives, improving the clinical relevance of the study, and ultimately developing higher quality, as well as safer and more efficient services (39). Evaluating subjective outcomes (such as comfort and self-confidence) could provide worthwhile research themes for further studies. As suggested by one qualitative study reporting on the re-use of hypnosis by women in later stressful situations, such as breastfeeding difficulties (31), the exploration of outcomes occurring in the post-partum period could be relevant. A recent study observed that the use of hypnosis enhanced the rates of skin-to-skin contact and breastfeeding duration (40). Further evidence suggests that a positive childbirth experience could help prevent postpartum depression (41). Defining these outcomes could provide homogenization, regarded as a necessary step toward patient-centred care (18), as in the CoRe Outcomes in Women's and Newborn health (CROWN) initiative (42). Integrating the views of patients, clinicians and researchers is a significant challenge, and our results provide some clues to achieving this. It 
is therefore essential to set up a genuine patient-centred perspective to take into account patient needs and expectations when determining outcomes for studies seeking to evaluate the efficacy of hypnosis (43).

\subsection{Similarities and differences in results}

Discrepancies were observed across qualitative and quantitative findings on intra-partum coping skills, reported to be better in case of hypnosis in qualitative studies and not as good in one RCT (11). We attempted to understand this divergence using a "reconciliation strategy" (44). Indeed, the mode of hypnosis administration in the RCT (group sessions) differed from the qualitative study interventions (mostly individual sessions) and this could have specific effects on intra-partum coping skills. Alternatively, women in the hypnosis group seemed to have had greater expectations regarding their coping skills after the course compared to a control group of women, as suggested by an evaluation of their perceived ability to cope during childbirth after course completion (31). Higher expectations could then lead to greater disappointment among women who received hypnosis than among those in the control group (31). This effect is known as a "response shift", defined as "a change in the meaning of one's self-evaluation of a target construct as a result of (a) a change in the respondent's internal standards of measurement (scale recalibration, in psychometric terms); (b) a change in the respondent's values; or (c) a redefinition of the target construct."(45). To address response shift, a patient-centred outcome tool has been developed (25), which makes possible to identify changes following resort to CAM (or other therapeutic interventions) in the context of chronic disease. The development of new tools for sub-acute or acute conditions would be useful. 
However, disappointment can also be related to poor communication. It is indeed worth noting that midwives may sometimes misinterpret the signs of labour as a result of the unexpectedly relaxed state of women under hypnosis. These misinterpretations could lead to delays in patient management and to feelings of frustration and disappointment (31). To avoid such delays, the staff should be trained and able to recognize a hypnosis-related state, and clinicians should ensure that the trance has really ended after delivery.

\subsection{Theoretical model of how hypnosis might work}

According to the theoretical model of hypnosis described in the introduction, the choice of primary outcomes related to medication (e.g. epidural anaesthesia) was consistent across quantitative studies and partially in qualitative studies. However, the meta-analysis did not support this hypothesis, as no significant differences between women in the hypnosis group and those in the control group were found for the use of epidural anaesthesia (7). In fact, outcomes directly associated with the sensory component of pain, such as the use of pharmacological analgesics or pain intensity, were not clearly associated with hypnosis, and were not found among the main themes emerging from the qualitative studies.

For invasive procedures (such as large-core breast biopsy or percutaneous tumour treatment), the use of hypnosis has been shown to reduce the use of painkillers $(46,47)$. Two factors could account for this difference between labour/childbirth and invasive procedures. Firstly for invasive medical/surgical procedures, the hypnotherapist is present during the whole procedure, which is not so for labour, implying that the presence of a therapist is a key element, as suggested by McAllister et al. (48). Secondly, hypnosis could mainly act on the affective component of pain, and not on the sensory component, suggesting that hypnosis may not prevent the appearance of pain, but that it helps to cope with it. An effect on the 
affective component of pain could be obtained using fear and anxiety reduction techniques (8) and techniques to increase confidence, to promote an active role and to boost inner security for women $(2,11,29-34)$. This could lead to lesser unpleasantness and more positive childbirth experiences. As reported in a functional magnetic resonance imagery study (fMRI), the affective component of pain and the sensory component of pain relate to different cortical areas, and it is possible to observe selective changes in the perceived unpleasantness of noxious stimuli without changes in the actual intensity. Finally, it is worth noting that only the largest RCT found an association between a positive childbirth experience and hypnosis (37).

\subsection{Implications for clinical practice and research}

Although no formal recommendations can be made regarding the clinical usefulness of hypnosis for pain management in labour and childbirth, several points can be underlined:

- As published studies have not reported any specific adverse events, and considering the positive reports from qualitative studies, there is no evidence to recommend avoiding the use of hypnosis, if it is the patient's wish.

- Hypnosis should not be presented as a means to reduce the use of pharmacological analgesics, but as a technique that can enable the patient to have a positive birth experience.

- The staff, especially in centres offering antenatal self-hypnosis sessions, should be trained to identify women likely to be using self-hypnosis when in active labour in order to avoid delays in patient management.

- This research underlines the potentially beneficial effect of having an accompanying person (either a partner (49) or a member of the medical staff (48)), a recognised means to enhance a patient-centred approach (20). 
The added value of mixed-method research provides clinicians with some important insights into the patient's perspective while enhancing the conceptual model for the mode of action of hypnosis. In addition, this research offers a link between clinical and research perspectives, which facilitates the initiation of patient-centred research with homogenized and hierarchical outcomes (50).

\subsection{Strengths and limitations}

This is the first study to combine both quantitative and qualitative results on hypnosis during labour and childbirth in an integrative model. Combining qualitative and quantitative findings showed the legitimacy of both paradigms as equally important sources of evidence (51). This new strategy enabled us to adopt a dialectic stance, adhering to Greene's idea that "engaging dialogically with paradigm differences can generatively yield new insights and understandings"(52). This is particularly relevant in the field of evaluation of complex interventions, since traditional methods have shown their limits (53).

Concerning our research strategy, as we included only peer-reviewed studies published in scientific outlets, we may have missed important studies from the grey literature. It can also be noted that qualitative data saturation was not fully achieved and more research is required to corroborate our findings. Further to this, the poor quality of the quantitative and qualitative studies included impacts the robustness of the present synthesis.

For both qualitative and quantitative studies, the heterogeneity of hypnosis interventions is a major limitation, questioning comparability across the studies included. However, we 
considered that these programs were based on the same core principle as in the Cochrane review (7).

Finally, our results are based on the choice of a reconciliation strategy for qualitative and quantitative data integration. This should be kept in mind, since the choice of a different data integration strategy could have yielded different results.

\section{Conclusion}

By integrating qualitative and quantitative findings, this study offers a comprehensive account of the efficacy of hypnosis for childbirth, which should not be presented as a means to reduce the use of pharmacological analgesics, but as a technique that can enable the patient to have a positive birth experience.

The joint analysis of quantitative assessments and subjective accounts of personal experiences highlighted the importance of considering outcomes that reflect the perspectives of patients, researchers, and clinicians when it comes to evaluating the efficacy of a complex intervention such as hypnosis for labour and childbirth. Although challenging, this appears as a necessary step toward patient-centred care. 


\section{References}

1. nccih. Hypnosis [Internet]. 2020 [cited 2020 Oct 27]. Available from: https://www.nccih.nih.gov/health/hypnosis

2. Mitchell M. Women's use of complementary and alternative medicine in pregnancy: A journey to normal birth. Br J Midwifery. 2013 Feb 5;21(2):100-6.

3. Anim-Somuah M, Smyth RM, Jones L. Epidural versus non-epidural or no analgesia in labour. Cochrane Database Syst Rev. 2018;(12):CD000331.

4. Attanasio L, Kozhimannil KB, Jou J, McPherson ME, Camann W. Women's Experiences with Neuraxial Labor Analgesia in the Listening to Mothers II Survey: A Content Analysis of OpenEnded Responses. Anesth Analg. 2015 Oct;121(4):974-80.

5. Elkins GR, Barabasz AF, Council JR, Spiegel D. Advancing Research and Practice: The Revised APA Division 30 Definition of Hypnosis. Am J Clin Hypn. 2015 Apr;57(4):378-85.

6. Dick-Read G. [Natural childbirth]. Med Klin Munich. 1957 Aug 16;52(33):1395-8.

7. Madden K, Middleton P, Cyna AM, Matthewson M, Jones L. Hypnosis for pain management during labour and childbirth. Cochrane Database Syst Rev. 2016 May 19;(5):CD009356.

8. Downe S, Finlayson K, Melvin C, Spiby H, Ali S, Diggle P, et al. Self-hypnosis for intrapartum pain management in pregnant nulliparous women: a randomised controlled trial of clinical effectiveness. BJOG. 2015;122(9):1226-34.

9. Werner A, Uldbjerg N, Zachariae R, Wu CS, Nohr EA. Antenatal hypnosis training and childbirth experience: a randomized controlled trial. Birth. 2013;40(4):272-80.

10. Cyna A, Crowther C, Robinson J, Andrew M, Antoniou G, Baghurst P. Hypnosis Antenatal Training for Childbirth: a randomised controlled trial. BJOG. 2013;120(10):1248-59.

11. Fisher B, Esplin S, Stoddard G, Silver R. Randomized controlled trial of hypnobirthing versus standard childbirth classes: patient satisfaction and attitudes towards labor. Am J Obstet Gynecol. 2009;201(6, Supplement):S61-2.

12. Freeman RM, Macaulay AJ, Eve L, Chamberlain GV, Bhat AV. Randomised trial of self hypnosis for analgesia in labour. Br Med J Clin Res Ed. 1986 Mar 8;292(6521):657-8.

13. Harmon TM, Hynan MT, Tyre TE. Improved obstetric outcomes using hypnotic analgesia and skill mastery combined with childbirth education. J Consult Clin Psychol. 1990 Oct;58(5):52530.

14. Martin AA, Schauble PG, Rai SH, Curry RW Jr. The effects of hypnosis on the labor processes and birth outcomes of pregnant adolescents. J Fam Pr. 2001 May;50(5):441-3.

15. Mehl-Madrona LE. Hypnosis to facilitate uncomplicated birth. Am J Clin Hypn. 2004 Apr;46(4):299-312. 
16. Rock NL, Shipley TE, Campbell C. Hypnosis with untrained, nonvolunteer patients in labor. Int J Clin Exp Hypn. 1969 Jan;17(1):25-36.

17. Craig P, Dieppe P, Macintyre S, Michie S, Nazareth I, Petticrew M. Developing and evaluating complex interventions: the new Medical Research Council guidance. BMJ. 2008;337:a1655.

18. Stewart M, Belle BJ, Weston WW, McWhinney IR, McWilliam CL, Freeman TR. Patient-Centered Medicine: Transforming the Clinical Method. 3rd ed. CRC Press; 2013. 442 p.

19. Epstein RM, Street RL. The Values and Value of Patient-Centered Care. Ann Fam Med. 2011 Mar 1;9(2):100-3.

20. Langberg EM, Dyhr L, Davidsen AS. Development of the concept of patient-centredness - A systematic review. Patient Educ Couns. 2019;102(7):1228-36.

21. Gerteis M, Edgman-Levitan S, Daley J, Delbanco T. Through the Patient's Eyes: Understanding and Promoting Patient-Centered Care. San Francisco, Californie: Jossey-Bass; 1993.

22. Romeyke T, Nöhammer E, Scheuer HC, Stummer H. Integration of naturopathic medicine into acute inpatient care: An approach for patient-centred medicine under diagnosis-related groups. Complement Ther Clin Pract. 2017 Aug 1;28:9-17.

23. Walach H, Falkenberg T, Fonnebo V, Lewith G, Jonas WB. Circular instead of hierarchical: methodological principles for the evaluation of complex interventions. BMC Med Res Methodol. 2006;6:29.

24. Hsu C, Sherman KJ, Eaves ER, Turner JA, Cherkin DC, Cromp D, et al. New perspectives on patient expectations of treatment outcomes: results from qualitative interviews with patients seeking complementary and alternative medicine treatments for chronic low back pain. BMC Complement Altern Med. 2014;14:276.

25. Ritenbaugh C, Nichter M, Nichter MA, Kelly KL, Sims CM, Bell IR, et al. Developing a patientcentered outcome measure for complementary and alternative medicine therapies I: defining content and format. BMC Complement Altern Med. 2011;11:135.

26. Creswell JW, Creswell JD. Research Design: Qualitative, Quantitative, and Mixed Methods Approaches. 5th ed. Sage Publications; 2018.

27. Mason J. Mixing methods in a qualitatively driven way. Qual Res. 2006;6(1):9-25.

28. Frantzen KK, Fetters MD. Meta-integration for synthesizing data in a systematic mixed studies review: insights from research on autism spectrum disorder. Qual Quant. 2015;1-27.

29. Abbasi M, Ghazi F, Barlow-Harrison A, Sheikhvatan M, Mohammadyari F. The effect of hypnosis on pain relief during labor and childbirth in Iranian pregnant women. Int J Clin Exp Hypn. 2009 Apr;57(2):174-83.

30. Isbir GG. My birth story is like a dream: a childbirth educator's childbirth. J Perinat Educ. 2013;22(1):23-9.

31. Finlayson K, Downe S, Hinder S, Carr H, Spiby H, Whorwell P. Unexpected consequences: women's experiences of a self-hypnosis intervention to help with pain relief during labour. BMC Pregnancy Childbirth. 2015 Sep 25;15:229. 
32. Jackson P. Hypnosis for birthing--A natural option: Part 2. Aust J Clin Hypnother Hypn. 2003;24(2):112-22.

33. Moore K, Burrows G. Hypnosis in childbirth. Aust J Clin Exp Hypn. 2002;30(1):35-44.

34. Sauer C, Oster MI. Obstetric hypnosis : two case studies. Aust J Clin Exp Hypn. 1997;25(1):74-9.

35. Walker WL. Improvised self-hypnosis for childbirth. Aust J Clin Exp Hypn. 2000;(28):100-2.

36. Cyna A. Case notes. A post-partum complication of hypnosis for analgesia during labour. Aust J Clin Exp Hypn. 2003;31(2):185-90.

37. Werner A, Uldbjerg N, Zachariae R, Rosen G, Nohr EA. Self-hypnosis for coping with labour pain: a randomised controlled trial. BJOG. 2013;120(3):346-53.

38. Angle P, Kurtz-Landy C, Djordjevic J, Barrett J, Kibbe A, Sriparamananthan S, et al. The Angle Labor Pain Questionnaire: Reliability, Validity, Sensitivity to Change, and Responsiveness During Early Active Labor Without Pain Relief. Clin J Pain. 2017 Feb;33(2):132.

39. Feeling better? Improving patient experience in hospital report [Internet]. NHS; 2010. Available from: www.nhsconfed.org

40. Atis FY, Rathfisch $\mathrm{G}$. The effect of hypnobirthing training given in the antenatal period on birth pain and fear. Complement Ther Clin Pract. 2018 Nov;33:77-84.

41. Sado M, Ota E, Stickley A, Mori R. Hypnosis during pregnancy, childbirth, and the postnatal period for preventing postnatal depression. Cochrane Database Syst Rev. 2012;6:CD009062.

42. Khan KS, Romero R, Chief Editors of Journals participating in CROWN Initiative. The CROWN initiative: journal editors invite researchers to develop core outcomes in women's health. Am J Obstet Gynecol. 2014 Dec;211(6):575-6.

43. Khan K. The CROWN Initiative: Journal editors invite researchers to develop core outcomes in women's health. Best Pract Res Clin Obstet Gynaecol. 2019 May 1;57:e1-4.

44. Pluye P, Grad RM, Levine A, Nicolau B. Understanding divergence of quantitative and qualitative data (or results) in mixed methods studies. Int J Mult Res Approaches. 2009 Apr 1;3(1):58-72.

45. Sprangers MAG, Schwartz CE. Integrating response shift into health-related quality of life research: A theoretical model. Soc Sci Med. 1999;48(11):1507-15.

46. Lang EV, Berbaum KS, Pauker SG, Faintuch S, Salazar GM, Lutgendorf S, et al. Beneficial effects of hypnosis and adverse effects of empathic attention during percutaneous tumor treatment: when being nice does not suffice. J Vasc Interv Radiol. 2008 Jun;19(6):897-905.

47. Lang EV, Berbaum KS, Faintuch S, Hatsiopoulou O, Halsey N, Li X, et al. Adjunctive self-hypnotic relaxation for outpatient medical procedures: a prospective randomized trial with women undergoing large core breast biopsy. Pain. 2006 Dec 15;126(1-3):155-64.

48. McAllister S, Coxon K, Murrells T, Sandall J. Healthcare professionals' attitudes, knowledge and self-efficacy levels regarding the use of self-hypnosis in childbirth: A prospective questionnaire survey. Midwifery. 2017 Apr 1;47:8-14. 
49. Guthrie K, Taylor DJ, Defriend D. Maternal hypnosis induced by husbands during childbirth. J Obstet Gynaecol. 1984 Jan 1;5(2):93-5.

50. Clesse C, Lighezzolo-Alnot J, de Lavergne S, Hamlin S, Scheffler M. The evolution of birth medicalisation: A systematic review. Midwifery. 2018 Nov 1;66:161-7.

51. Hall B, Howard K. A Synergistic Approach: Conducting Mixed Methods Research With Typological and Systemic Design Considerations. J Mix Methods Res. 2008 Jul 1;2(3):248-69.

52. Greene JC. Is Mixed Methods Social Inquiry a Distinctive Methodology? J Mix Methods Res. 2008 Jan 1;2(1):7-22.

53. Campbell M, Fitzpatrick R, Haines A, Kinmonth AL, Sandercock P, Spiegelhalter D, et al. Framework for design and evaluation of complex interventions to improve health. BMJ. 2000 Sep 16;321(7262):694-6. 
Figure 1. Theoretical model: Dick-Read fear-tension-pain cycle

Figure 2. Qualitative studies search strategy - flow chart and search strategy

Table 1: Description of qualitative studies and case studies included

Table 2: Quality appraisal of qualitative studies (CASP tool)

Table 3: Qualitative studies: main findings

Figure 3: Similitudes and discrepancies between main outcomes and main themes in quantitative and qualitative studies

Figure 4: Similitudes and discrepancies between results from qualitative and quantitative studies

Figure 5.Theoretical model for how hypnosis might work 